\title{
Effects of body mass index and range of motion on intraoperative change in pelvic tilt during total hip arthroplasty using the direct anterior approach
}

\author{
Masanori Okamoto ${ }^{1 *}$, Masashi Kawasaki², Toshiaki Okura², Taisuke Seki ${ }^{1}$ and Shiro Imagama ${ }^{1}$
}

\begin{abstract}
Background: Intraoperative pelvic tilt changes that occurs during total hip arthroplasty (THA) in the supine position affects cup placement and sometimes causes malalignment. The relationship between body mass index (BMI) and pelvic movement has been reported for some procedures, but not the direct anterior approach (DAA). The purpose of this study was to investigate intraoperative pelvic tilt changes that occurs during DAA.

Methods: In this single-center, retrospective study, we reviewed 200 hips that underwent primary THA via DAA in the supine position using an accelerometer-based navigation system. Intraoperative changes in pelvic tilt and axial rotation from the start of surgery to cup placement were assessed using the navigation system. Preoperative clinical factors that increased pelvic tilt and axial rotation toward the surgical side by $>10^{\circ}$ were analyzed via univariate and multiple logistic regression analyses.

Results: The mean pelvic tilt value increased by $7.6^{\circ} \pm 3.8^{\circ}$ (95\% confidence interval [Cl], 7.1-8.2; range, $-5.0-19.0$ ) intraoperatively, and the axial rotation increased by $3.2^{\circ} \pm 2.7^{\circ}(95 \% \mathrm{Cl}, 2.7-3.7$; range, $-13.0-12.0)$. Univariate analysis revealed that the group with increased pelvic tilt showed significantly greater range of abduction and internal rotation, and significantly lower BMI than the group with no increased tilt. Pre-incisional pelvic tilt was significantly greater in the group with increased axial rotation than in the group with no increased rotation. On logistic regression analysis, BMI (odds ratio [OR], $0.889 ; 95 \% \mathrm{Cl}, 0.809-0.977 ; p=0.014$ ) and the range of internal rotation $(\mathrm{OR}, 1.310 ; 95 \% \mathrm{Cl}, 1.002-1.061 ; p=0.038)$ were predictors of large increases in pelvic tilt. No predictors of large increases in axial rotation were identified.

Conclusion: Significant forward pelvic tilt was observed in patients with a low BMI values and high ranges of internal rotation via THA using the DAA. Findings indicated that surgeons should pay attention to intraoperative pelvic movements, which may help identify patients with significant pelvic tilt changes.
\end{abstract}

Keywords: Total hip Arthroplasty, Direct anterior approach, Pelvic tilt, Accelerometer-based navigation system

\footnotetext{
* Correspondence: masaokamotoo@yahoo.co.jp

'Department of Orthopaedic Surgery, Nagoya University Graduate School of Medicine, 65 Tsurumai-cho, Showa-ku, Nagoya, Aichi 466-8550, Japan

Full list of author information is available at the end of the article
}

(c) The Author(s). 2021 Open Access This article is licensed under a Creative Commons Attribution 4.0 International License, which permits use, sharing, adaptation, distribution and reproduction in any medium or format, as long as you give appropriate credit to the original author(s) and the source, provide a link to the Creative Commons licence, and indicate if changes were made. The images or other third party material in this article are included in the article's Creative Commons licence, unless indicated otherwise in a credit line to the material. If material is not included in the article's Creative Commons licence and your intended use is not permitted by statutory regulation or exceeds the permitted use, you will need to obtain permission directly from the copyright holder. To view a copy of this licence, visit http://creativecommons.org/licenses/by/4.0/. The Creative Commons Public Domain Dedication waiver (http://creativecommons.org/publicdomain/zero/1.0/) applies to the data made available in this article, unless otherwise stated in a credit line to the data. 


\section{Introduction}

Accurate cup positioning is important for achieving hip stability and good long-term outcomes in patients undergoing total hip arthroplasty (THA) [1,2]. The position of the cup affects joint stability, polyethylene wear, ceramic damage, and risk of metallosis [3-5]. The concept of a "safe zone" for cup placement was reported by Lewnik in 1978 [6]. In recent years, some authors have reported that the ideal safe zone is narrower than that which has been traditionally reported [7, 8]. In addition, the range of anteversion is smaller than the range of inclination [9].

The direct anterior approach (DAA) is an intramuscular approach applied while the patient is positioned in the supine position. Advantages of DAA are as follows: minimal soft tissue damage and rapid postoperative recovery [10-12]. Cup positioning outside the safe zone may occur during THA via the DAA when the freehand technique without a navigation system is used [13]. Some reports show that cup anteversion is larger after using the DAA compared with the posterior approach $[14,15]$. Pelvic movement during cup implantation is a major factor affecting cup positioning $[16,17]$. The use of navigation systems for positioning of cups improves the accuracy of placement, reduces rates of dislocation, and minimizes the occurrence of aseptic revision of the acetabular component. Nevertheless, the proportion of THA procedures that use navigation is small, and the conventional procedure without navigation remains the gold standard [18]. Surgeons who perform conventional THA need to understand the significance of pelvic movements intraoperatively. It has been reported that in the supine position, pelvic tilt changes are associated with the patient's body mass index (BMI) when using both lateral and anterolateral approaches $[19,20]$. Interestingly, the relationship between BMI and pelvic tilt change of each approach differ. However, the associations between the DAA and BMI have not been reported.

HipAlign (OrthoAlign Inc., Aliso, U.S.A.) is an accelerometer-based, portable navigation system that is used for intraoperative pelvic tracking. The system displays the cup angle throughout THA in the supine position, and its use facilitates accurate cup placement [21]. On its display, the system indicates intraoperative pelvic motion in both sagittal and axial planes.

We hypothesized that the cup has a large anteversion angle that causes the pelvis to tilt forward (or lean) toward the operation side and that the functional pelvic plane at the start of surgery differs from the table plane during cup insertion. Thus, this study aimed to investigate intraoperative pelvic movements in THA via the DAA using an accelerometer-based navigation system to determine clinical factors associated with movement that results in abnormal cup positioning.

\section{Materials and methods}

\section{Patients}

The institutional review board approved this singlecenter, retrospective study. All study participants provided written informed consent. Primary THA for osteoarthritis was performed using the DAA on 256 consecutive hips of 235 patients from November 2017 to November 2019. Cementless or hybrid primary THA using the HipAlign portable navigation system was performed on 218 hips of 200 patients. Two hips with a history of osteotomy, 14 with simultaneous bilateral surgery, and 2 with data loss were excluded from the study; thus, we analyzed 200 hips of 189 patients. No patients experienced the loosening of pins that secured the HipAlign unit to the ilium.

\section{Surgical procedures}

All surgeries were performed under general anesthesia, and the range of motion (ROM) of the hip in the supine position was measured before surgery. All THAs were performed via the same procedure by three surgeons using the DAA with the patient in the supine position on a standard operating table. HipAlign was used in accordance with a procedure previously described [21]. The main unit was placed on the iliac crest on the affected side, and registration was performed before the first skin incision. Two 4.0-mm fixation pins were inserted into the iliac crest on the affected side to fix the navigation unit. The direction of gravitational acceleration was then registered. The anterior superior iliac spine (ASIS) and pubic tubercle were registered as landmarks by placing the pointer on the overlying skin. Then, the sensor was attached to the main unit. Pelvic tilt and axial rotation with reference to the functional pelvic plane were displayed on the screen of main unit (Fig. 1). A 7-cm skin incision was made to enter the intermuscular plane between the tensor fasciae latae and sartorius muscles. Labrum resection, acetabular reaming, and cup placement were performed while preserving the lower portion of the anterior and posterior capsules with three acetabular retractors. The anterior and anteriorinferior retractors were pulled and held using Magic Tower (Zimmer Biomet Holdings. IN, USA), and the posterior retractor was pulled using a $1.35-\mathrm{kg}$ weight (DepuySynthes, Warsaw, IN, USA) (Fig. 2). The capsule in the inferior band of the iliofemoral ligament was incised. The superior band of the iliofemoral ligament, ischiofemoral ligament, and the conjoined external rotator tendon were preserved.

The cup was placed after determining the target angle, which was displayed on the screen of the navigation system. While looking at the display screen, the operator impacted the cup inserter with the hammer and placed the cup (Figs. 1, 3). The target angle of cup orientation 


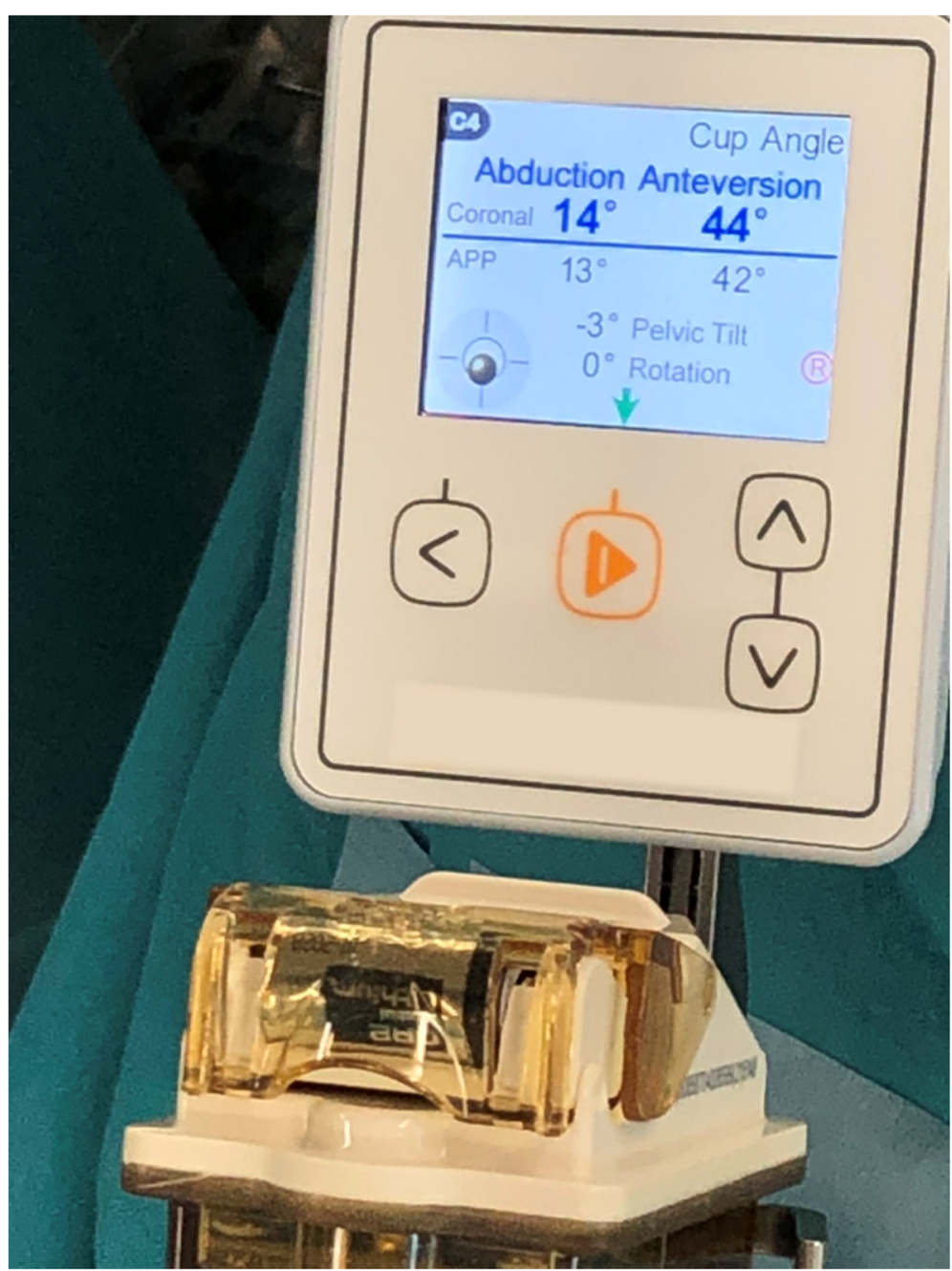

Fig. 1 On the screen of the main unit, inclination and anteversion are displayed in radiographic values during cup insertion and after cup placement. Pelvic tilt and rotation are displayed at any given point in time

was $40^{\circ}$ inclination and $15^{\circ}$ anteversion, which were based on radiographic definition. The following acetabular components and liners were used: G7 acetabular cup, and E1 or Biolox Delta ceramic liners (Zimmer Biomet Inc., Warsaw, IN, USA). The following femoral components were used: Taperloc Complete Microplasty, or CMK (Charnley Modified Kerboul) Original Concept stem (Zimmer Biomet Inc., Warsaw, IN, USA).

\section{Measurements}

Pelvic angles were measured using the HipAlign system during navigation system registration at the time of cup placement to the acetabulum using the impactor, prior to removing the cup from the impactor. The angle of the sagittal plane against the horizontal plane was defined as the pelvic tilt. Forward tilt was positive, and posterior tilt was negative. The angle on the coronal plane was defined as axial rotation. The lean toward the surgical side was positive, and the rise was negative (Fig. 4). We measured changes in pelvic tilt and axial rotation from registration to cup placement. ROM was measured using a goniometer by two orthoepic surgeons (T.O and M.O). One person steadied the patient and the other stood on the evaluation side to measure relevant angles, which were recorded in degrees. For flexion measurements, only the leg to be measured was placed in maximum flexion. The evaluator placed one side of the goniometer horizontally on the surgical table and the other side parallel to the proximal thigh. Abduction and adduction were set to their maximum angles. The evaluator placed one side of the goniometer on the ASIS and measured the other side parallel to the thigh. For internal and external rotation, the patient's hip was flexed $90^{\circ}$. When the angle of flexion was less than $90^{\circ}$, the patient was placed in maximum flexion. The angle between the lower leg axis and the body axis around the knee 


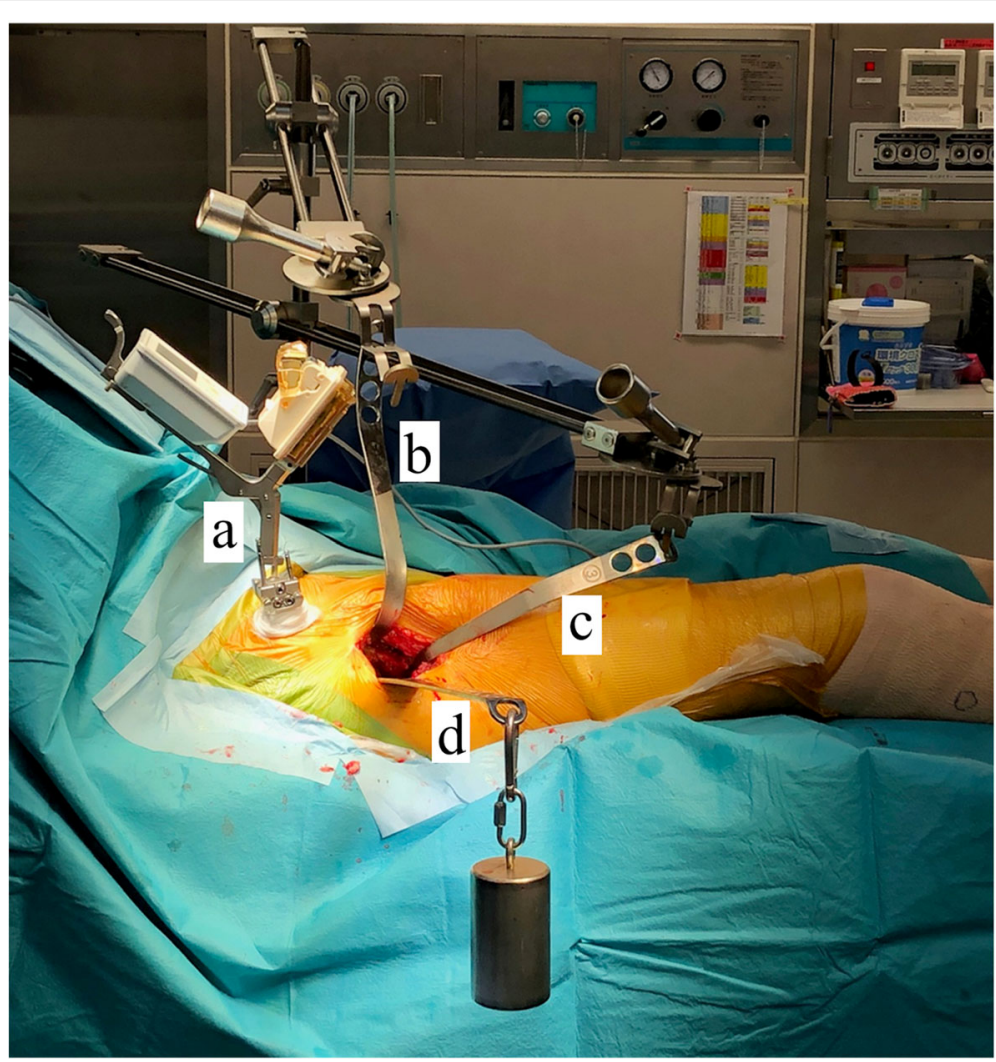

Fig. 2 (a) HipAlign (OrthoAlign Inc., Aliso, U.S.A.) is placed on the iliac wing on the surgical side. In the picture, the sensor is attached to the unit. $\mathbf{b}, \mathbf{c}$ The anterior retractor and distal retractor are held by a retractor holding device (Magic Tower, Zimmer-Biomet). $\mathbf{d}$ The posterior retractor is pulled using a $1.35 \mathrm{~kg}$ weight (DepuySynthes)

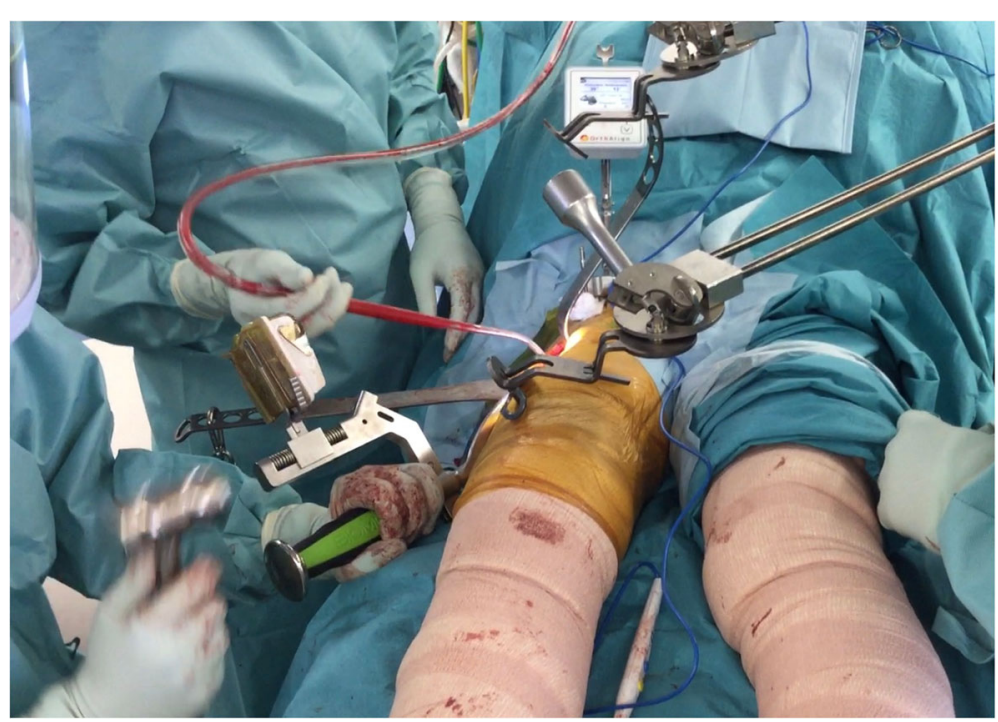

Fig. 3 The sensor is fitted on the cup insertion handle. Inclination and anteversion are displayed in radiographic values on the screen of the main unit in real time 


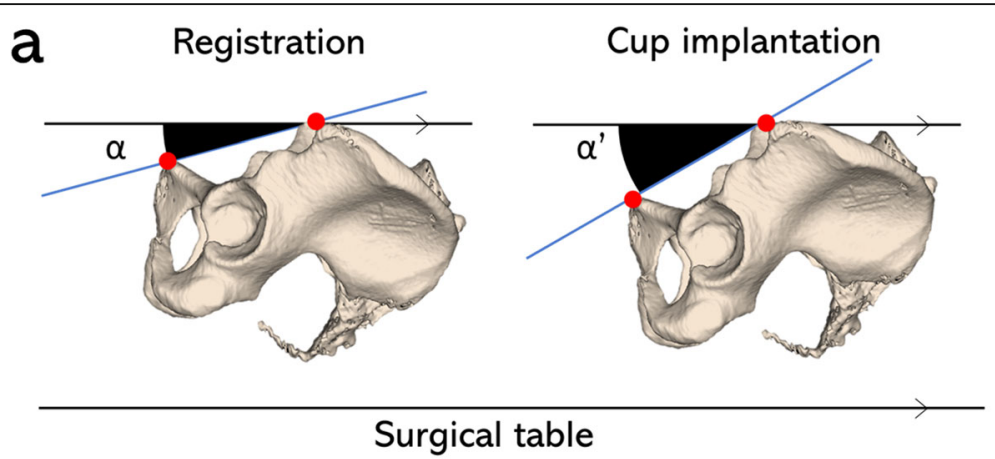

b Registration Cup implantation
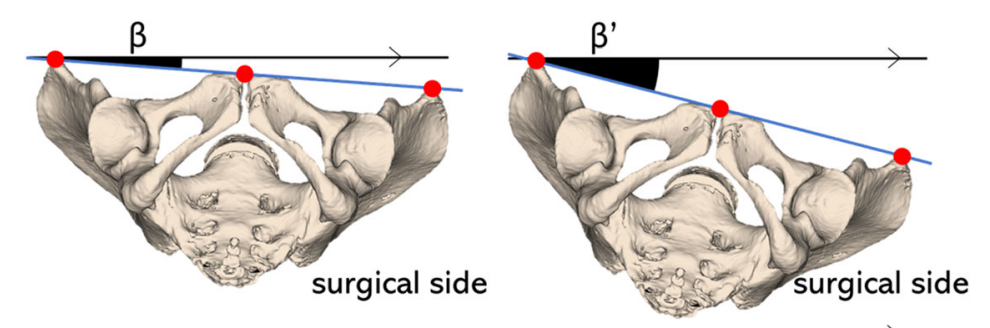

Surgical table

Fig. 4 a Pelvic tilt is measured as the anterior tilt angle of the anterior pelvic plane in the sagittal plane toward the surgical table ( $a$, $\left.a^{\prime}\right)$. Pelvic tilt change is calculated by subtracting a from $a^{\prime}$. Anterior tilt is given a positive value, and posterior tilt is negative. $\mathbf{b}$ Axial rotation is the lean of the anterior pelvic plane in the axal plane toward surgical side $\left(\beta, \beta^{\prime}\right)$. Lean toward the surgical side is given a positive value, and rise is negative. The difference in pelvic tilt toward the surgical side from registration to cup implantation is defined as change in axial rotation. The angle is calculated by subtracting $\beta$ from $\beta^{\prime}$

was measured. Extension was not measured, as the patient was under anesthesia in the supine position.

Two cohorts with pelvic movements were compared; those who presented with $\geq 10^{\circ}$ change in pelvic tilt and axial rotation were placed into the increased tilt group, while those who presented with $<10^{\circ}$ pelvic tilt and axial rotation were placed into the minor tilt group. The inclination or anteversion of the historical Lewnick's safe zone of the cup was in the range of $\pm 10^{\circ}$ [6]. In addition, it was assumed that the pelvis would tilt forward because cup anteversion was larger in the group using the DAA $[14,15]$. Therefore, a $10^{\circ}$ increase was used as the reference. Explanatory variables were sex, age, BMI, KellgrenLawrence (KL) grade, Crowe's classification, pelvic tilt before incision and preoperative ROM, flexion, abduction, adduction, external rotation and internal rotation, which surgeons assessed in the operating room.

\section{Statistical analysis}

Changes in pelvic position were compared using a paired $t$-test. Univariate analyses of groups were estimated using the Fisher's exact test or the Mann-Whitney Utest, since continuous variables were not normally distributed. Multivariate logistic regression analyses were performed to estimate risk of increased pelvic tilt and axial rotation. All variables in which $P<0.1$ in the univariate analysis were considered independent variables. $P$-values less than 0.05 were considered statistically significant. All statistical analyses were performed using SPSS Ver. 26 (IBM Corp. Armonk, NY, USA) or EZR (Saitama Medical Center, Jichi Medical University, Saitama, Japan).

\section{Results}

The study included 164 women and 36 men. The average age of study participants was $69.0 \pm 9.6$ years (range, $40-90$ years). The average height of participants was $153.0 \pm 8.9 \mathrm{~cm}$ (range, $134-180 \mathrm{~cm}$ ), the average weight was $56.2 \pm 12.0 \mathrm{~kg}$ (range, $35.8-94.6 \mathrm{~kg}$ ), and the mean BMI was $24.1 \pm 3.9 \mathrm{~kg} / \mathrm{m}^{2}$ (range, $17.3-37.7 \mathrm{~kg} / \mathrm{m}^{2}$ ). Based on Crowe's classification, 193 hips were grade I, 6 were grade II, 1 was grade III, and no hips were grade IV. Based on the KL grading scale, 4 hips were grade 2, 45 were grade 3 , and 151 were grade 4 (Table 1 ).

Intraoperative pelvic tilt increased by $7.6^{\circ} \pm 3.8^{\circ}(95 \%$ CI, 7.1-8.2; range, -5.0-19.0), while axial rotation increased by $3.2^{\circ} \pm 2.7^{\circ}$ (95\% CI, 2.7-3.7; range, - 13.012.0) (Table 2). Univariate analyses revealed that in female patients, the preoperative range of abduction and internal rotation were significantly greater than those in 
Table 1 Patient demographics

\begin{tabular}{ll}
\hline Sex $($ female/male) & $\mathbf{1 6 4 / 3 6}$ \\
\hline Age (years) & $69.0 \pm 9.6(40-90)$ \\
Height $(\mathrm{cm})$ & $153.0 \pm 8.9(134-180)$ \\
Weight $(\mathrm{kg})$ & $56.2 \pm 12.0(35.8-94.6)$ \\
$\mathrm{BMl}\left(\mathrm{kg} / \mathrm{m}^{2}\right)$ & $24.1 \pm 3.9(17.3-37.7)$ \\
$\mathrm{K}-\mathrm{L}$ grade $(1 / 2 / 3 / 4)$ & $0 / 4 / 45 / 151$ \\
Crowe's classification (I/II/II/IV) & $193 / 6 / 1 / 0$
\end{tabular}

Values are provided as means \pm standard deviation (range from minimum to maximum)

$B M I$ body mass index, $K-L$ grade Kellgren-Lawrence grade

male patients, and BMI was significantly lower in patients with a large increase in pelvic tilt than in patients with no pelvic tilt increase (Table 3). Pelvic tilt at the beginning of the surgery was significantly increased in patients with large increases in pelvic axial rotation angle (Table 4). Other variables assessed did not significantly differ. Logistic regression analyses revealed that, BMI (OR, 0.889; 95\% CI, 0.809-0.977; $p=$ $0.014)$ and range of internal rotation (OR, 1.310; 95\% CI, $1.002-1.061 ; p=0.038)$ were predictors of a large increase in pelvic tilt. Logistic regression analysis indicated that pelvic tilt at the start of surgery was not a predictor of a large increase in axial rotation (Table 5).

\section{Discussion}

This study investigated intraoperative pelvic tilt during THA via the DAA when the procedure was performed using an accelerometer-based navigation system. Our results showed that the pelvis tilted forward in the sagittal plane and leaned toward the surgical side in the axial plane. Low BMI and an increased range of internal rotation could indicate a $>10^{\circ}$ increase in pelvic tilt. In contrast, there factor significantly predicted axial rotation.

Several studies reported that intraoperative pelvic movement occurs in the supine position during THA and that movement is associated with patient BMI. In the supine position, the relationship between BMI and pelvic motion associated with various approaches differ. Brodt et al. demonstrated that when the lateral approach was used, the pelvis tilted $-4.4^{\circ}$ in the axial plane intraoperatively. Patients with a high BMI leaned more toward the opposite side than patients with lower BMI values. In contrast, there was no significant change observed in the sagittal plane [19]. Kamenaga et al. demonstrated that when the anterolateral supine approach (ALS) was used, the average forward change in pelvic tilt measured using HipAlign was $2.7^{\circ}$, and the average tilt toward the surgical side in axial rotation was $1.2^{\circ}$. The change in absolute axial rotation was significantly negatively correlated with BMI. The change in sagittal pelvic tilt was not associated with BMI [20].

To the best of our knowledge, this is the first study to review the association between pelvic movement and BMI when the DAA is applied. It is also the first to evaluate associations between clinical factors such as stage of osteoarthritis, ROM, and outcomes of the various surgical approaches in the supine position. Changes in axial rotation were the opposite when the anterior approach, including DAA and ALS, were used versus the lateral approach. Brodt et al. reported that in the lateral approach a strong upward traction was required to provide the surgeon with sufficient visualization [19]. In contrast, the anterior approach may have been strongly influenced by posterior strength retractors in patients with low BMI values. In this study, a low BMI was a predictor of increased pelvic tilt. The anterior distal retractor pulled strongly in order to not avoid interfering with soft tissues throughout cup implantation. At that time, the retractor was pressed downward from the front of the thigh (Fig. 1). As a result, it was inferred that a force was applied to the distal pelvis and the pelvis tilted forward. A Finite Element Method study of effects of mattresses indicated that when lying on a mattress in supine position, a thin person will sink deeper into mattresses than an obese person when the same force is applied [22]. Patients with a low BMI values are expected to move more on the surgical table when surgical procedures are performed, and the pelvis should tilt in a more anterior direction. Large internal rotation was a predictor of increasing pelvic tilt. Spinal flexibility in the sagittal plane was positively correlated with internal rotation ROM [23]. Large tilt angles tended to result in varied pelvic positioning. The ischial femoral ligament provided internal rotational stability [24], and external rotation that antagonized internal rotation was performed by external rotator muscles. The posterior capsule and short rotator were preserved in THA via

Table 2 Pelvic movements (changes in pelvic tilt and axial rotation) from the start of surgery to cup placement

\begin{tabular}{|c|c|c|c|c|c|c|}
\hline & $\begin{array}{l}\text { At start of surgery } \\
\text { (Min, Max) }\end{array}$ & $\begin{array}{l}\text { At cup placement } \\
\text { (Min, Max) }\end{array}$ & $\begin{array}{l}\text { Mean of difference } \\
\text { (Min, Max) }\end{array}$ & $\begin{array}{l}\text { SD of } \\
\text { difference }\end{array}$ & $\begin{array}{l}95 \% \mathrm{Cl} \text { of } \\
\text { difference }\end{array}$ & $\begin{array}{l}P \\
\text { value } \\
a\end{array}$ \\
\hline Pelvic tilt $\left(^{\circ}\right)$ & $-7.4(-39.0,7.0)$ & $0.2(-33.0,16.0)$ & $7.6(-5.0,19.0)$ & 3.8 & $7.1-8.2$ & $<0.001$ \\
\hline Axial rotation $\left(^{\circ}\right)$ & $0.8(-10.0,7.0)$ & $4.0(-9.0,12.0)$ & $3.2(-13.0,12.0)$ & 3.7 & $2.7-3.7$ & $<0.001$ \\
\hline
\end{tabular}

$S D$ standard deviation, $\mathrm{Cl}$ confidence interval

a Mann-Whitney U test 
Table 3 Univariate analysis between increasing group and non-increasing group in change of pelvic tilt

\begin{tabular}{|c|c|c|c|}
\hline & $\begin{array}{l}\text { Increasing group } \\
\text { (51 hips) }\end{array}$ & $\begin{array}{l}\text { Non-increasing group } \\
\text { (149 hips) }\end{array}$ & $\begin{array}{l}P \\
\text { value }\end{array}$ \\
\hline Sex (female/male) & $48 / 3$ & $116 / 33$ & $0.010^{\mathrm{a}}$ \\
\hline Age (years) & $68.8 \pm 8.7$ & $67.6 \pm 10.0$ & $0.687^{b}$ \\
\hline $\mathrm{BMI}\left(\mathrm{kg} / \mathrm{m}^{2}\right)$ & $23.3 \pm 4.1$ & $25.1 \pm 3.7$ & $0.001^{b}$ \\
\hline K-L grade $(1 / 2 / 3 / 4)$ & $0 / 1 / 14 / 36$ & 0/3/31/115 & $0.248^{\mathrm{a}}$ \\
\hline Crowe's classification (I/II/III/IV) & $0 / 48 / 2 / 1$ & 0/145/4/0 & $0.193^{\mathrm{a}}$ \\
\hline Pelvic tilt at the start of surgery $\left(^{\circ}\right)$ & $-6.5 \pm 5.9$ & $-7.8 \pm 6.6$ & $0.167^{b}$ \\
\hline \multicolumn{4}{|l|}{$\mathrm{ROM}\left({ }^{\circ}\right)$} \\
\hline Flexion & $111.9 \pm 14.8$ & $108.4 \pm 17.5$ & $0.315^{b}$ \\
\hline Abduction & $35.7 \pm 15.7$ & $31.0 \pm 10.1$ & $0.044^{b}$ \\
\hline Adduction & $18.5 \pm 6.7$ & $17.1 \pm 6.3$ & $0.188^{b}$ \\
\hline External rotation & $43.5 \pm 10.2$ & $41.3 \pm 11.3$ & $0.399^{b}$ \\
\hline Internal rotation & $33.2 \pm 13.8$ & $25.6 \pm 13.5$ & $0.001^{b}$ \\
\hline
\end{tabular}

$B M I$ body mass index, $K$ - $L$ grade Kellgren-Lawrence grade, $R O M$ range of motion

${ }^{a}$ Fisher's exact test. ${ }^{b}$ Mann-Whitney $U$ test

DAA using a procedure that was based on a previous study [12]. In hip joints with small ROM of internal rotation, contracture of the posterior soft tissue may have suppressed the dorsal shift of the acetabula relative to the position of the femur. In cases where the range of internal rotation was large, the shift may not have suppressed movement, and the change of pelvic tilt tended to be large. BMI was not a predictor of unexpectedly increased axial rotation. In ALS, which is an anterior approach similar to DAA, a correlation between BMI and the absolute value of axial rotation was observed by Kamenaga et al. [20]. They described that the effect of traction may be large in patients with low BMI values. However, they reported that there was no correlation between real axial rotation values and BMI. The forces of the anterior and posterior retractors may offset each other, and one may not consistently dominate the other. Further research evaluating body pressure distribution and cadaver studies that measure the position of the femur and pelvis will be needed to elucidate mechanical mechanisms of the phenomenon.

Movement of the pelvis affects cup placement [16]. It has been reported that the DAA is associated a larger cup anteversion compared with the posterior approach $[14,15]$. Forward tilting of the pelvis and deviation to the surgical side could cause increased anteversion because insertion of the cup against the surgical table may widen the target angle to a degree larger than that

Table 4 Univariate analysis between increasing group and non-increasing group in change of axial rotation

\begin{tabular}{|c|c|c|c|}
\hline & $\begin{array}{l}\text { Increasing group } \\
\text { (11 hips) }\end{array}$ & $\begin{array}{l}\text { Non-increasing group } \\
\text { (189 hips) }\end{array}$ & $\begin{array}{l}P \\
\text { value }\end{array}$ \\
\hline Sex (female/male) & $9 / 2$ & $155 / 34$ & $1.000^{\mathrm{a}}$ \\
\hline Age (years) & $68.0 \pm 10.4$ & $67.9 \pm 9.7$ & $0.942^{b}$ \\
\hline $\mathrm{BMI}\left(\mathrm{kg} / \mathrm{m}^{2}\right)$ & $23.0 \pm 4.6$ & $24.7 \pm 3.8$ & $0.139^{b}$ \\
\hline K-L grade $(1 / 2 / 3 / 4)$ & $11 / 0 / 0 / 0$ & $182 / 6 / 1 / 0$ & $0.788^{\mathrm{a}}$ \\
\hline Crowe's classification (I/II/III/IV) & 0/0/3/8 & 0/4/42/143 & $1.000^{\mathrm{a}}$ \\
\hline Pelvic tilt at the start of surgery $\left(^{\circ}\right)$ & $-5.5 \pm 11.7$ & $-7.5 \pm 6.0$ & $0.021^{\mathrm{b}}$ \\
\hline \multicolumn{4}{|l|}{$\mathrm{ROM}\left({ }^{\circ}\right)$} \\
\hline Flexion & $105.9 \pm 22.3$ & $109.5 \pm 16.6$ & $0.806^{\mathrm{b}}$ \\
\hline Abduction & $34.1 \pm 13.9$ & $32.1 \pm 11.8$ & $0.289^{b}$ \\
\hline Adduction & $19.1 \pm 11.1$ & $17.4 \pm 6.1$ & $0.654^{b}$ \\
\hline External rotation & $39.5 \pm 13.1$ & $42.0 \pm 10.9$ & $0.579^{b}$ \\
\hline Internal rotation & $27.3 \pm 21.4$ & $27.6 \pm 13.5$ & $0.771^{\mathrm{b}}$ \\
\hline
\end{tabular}

$B M I$ body mass index, $K-L$ grade Kellgren-Lawrence grade, $R O M$ range of motion

a Fisher's exact test. ${ }^{\text {b }}$ Mann-Whitney $\mathrm{U}$ test., 
Table 5 Logistic regression for pelvic movements (enlargement in pelvic tilt and axial rotation)

\begin{tabular}{|c|c|c|c|c|c|}
\hline Objective variable & Explanatory variable & Odds ratio & $\begin{array}{l}95 \% \mathrm{Cl} \\
\text { for odds ratio }\end{array}$ & $P$ value & Nagelkerke $\mathrm{R}^{2}$ \\
\hline \multirow[t]{5}{*}{ Enlargement in pelvic tilt } & (constant) & 0.628 & & 0.745 & 0.150 \\
\hline & female & 2.635 & $0.734-9.460$ & 0.137 & \\
\hline & BMl & 0.889 & $0.809-0.977$ & 0.014 & \\
\hline & abduction & 1.015 & $0.982-1.050$ & 0.365 & \\
\hline & internal rotation & 1.031 & $1.002-1.061$ & 0.038 & \\
\hline \multirow[t]{2}{*}{ Enlargement in axial rotation } & (constant) & 0.082 & & & 0.015 \\
\hline & pelvic tilt at the start of surgery & 1.054 & $0.952-1.167$ & 0.311 & \\
\hline
\end{tabular}

$C /$ confidence interval, $B M I$ body mass index

of the functional pelvic plane. When pelvic tilt increased by $7.6^{\circ}$ and the cup was inserted using a mechanical guide with a radiographic inclination of $40^{\circ}$ and anteversion of $15^{\circ}$, anteversion of the placed cup was approximately $5.7^{\circ}$ larger than the target angle (calculated using Murry's definition) [22]. If deviation in the axial plane increased, anteversion was further increased. The angle deviated significantly from the narrow safe zone that has been proposed in recent years, which specifies a range of $\pm 5^{\circ}[7,8]$. High cup anteversion caused anterior dislocation [9], which lead to concerns of anterior instability of the hip joint. To position the cup accurately, a device that tracked pelvic movements was useful [21]. However, many THAs are not computer-assisted [18].

This study had several limitations. First, it was a single-center study, and its results may not be generalizable. Results may have varied if the assistant used a retractor. However, in this study, retractors were fixed with retractor holding devices and weights. Second, ROM was manually measured under anesthesia, and did not truly represent the angle formed by the pelvis and the femur. The angle measured under anesthesia could have been exaggerated due to movement of the pelvis during measurement. Furthermore, low BMI values may have influenced degree of error associated with ROM measurement. Internal rotation angle remains a predictor of pelvic movement. Third, pelvic tilt with all retractors removed was not measured. It was also not confirmed whether pelvic movement and cup malposition were suppressed by removing all retractors and installing a cup. In addition, the threshold of a large increase of $10^{\circ}$ might not have been appropriate. However, as the safe zone is controversial, clinically meaningful pelvic movement has not been determined. When anteversion based on an operative definition increased by $10^{\circ}$, anteversion based on a radiographic definition increased by $7.5^{\circ}$. We believe this discrepancy is a matter of concern. Finally, this cohort had low BMI values. The subjects in this cohort were all Japanese. In Japan, many individuals have a low BMI values. A cohort that has many obese patients may have experienced different outcomes. Future studies should aim to verify that patients with low BMI values and a large range of internal rotation have large cup anteversion values when a navigation system is not used.

\section{Conclusion}

This study characterized pelvic forward tilt and axial rotation during THA via the DAA. Predictors of pelvic forward tilt were low BMI and high internal rotation range. The surgeon should pay attention to pelvic tilt changes when inserting the cup when no device, such as a navigation system, is used to track pelvic movements. This study has the potential to help surgeons identify patients at increased risk of intraoperative pelvic tilt change.

\section{Abbreviations \\ THA: Total hip arthroplasty; BMI: Body mass index; DAA: Direct anterior approach; ROM: Range of motion; ALS: Anterolateral supine approach; ASIS: anterior superior iliac spine; KL: Kellgren Lawrence}

\section{Acknowledgements}

Not applicable.

\section{Authors' contributions}

All authors contributed to the study conception and design. The data were collected and analyzed by MO, TO, and MK. The first draft of the manuscript was written by $\mathrm{MO}$ and revised by MK and TS. SI oversaw the study. All authors commented on previous versions of the manuscript. All authors read and approved the final manuscript.

\section{Funding}

Not applicable.

\section{Availability of data and materials}

The datasets used and/or analyzed during the current study are available from the corresponding author on reasonable request.

\section{Declarations}

Ethics approval and consent to participate

All study participants provided informed consent, and the study design was approved by the appropriate ethics review board of Aichi Koseiren Konan Kosei Hospital (No. 30-011) and written informed consent was obtained from all participants. All procedures were in accordance with the principles of the Declaration of Helsinki.

Consent for publication

Not applicable. 


\section{Competing interests}

The authors declare that they have no competing interests.

\section{Author details}

'Department of Orthopaedic Surgery, Nagoya University Graduate School of Medicine, 65 Tsurumai-cho, Showa-ku, Nagoya, Aichi 466-8550, Japan. 2Department of Orthopaedic Surgery, Aichi Koseiren Konan Kosei Hospital, Konan, Aichi, Japan.

Received: 16 December 2020 Accepted: 15 February 2021

Published online: 02 March 2021

\section{References}

1. Jolles BM, Genoud P, Hoffmeyer P. Computer-assisted cup placement techniques in total hip arthroplasty improve accuracy of placement. Clin Orthop Relat Res. 2004;426:174-9.

2. Tsukada S, Wakui M. Decreased accuracy of acetabular cup placement for imageless navigation in obese patients. J Orthop Sci. 2010;15:758-63.

3. Patil S, Bergula A, Chen PC, Colwell CW Jr, D'Lima DD. Polyethylene wear and acetabular component orientation. J Bone Joint Surg Am. 2003;85:5663.

4. Tai SM, Munir S, Walter WL, Pearce SJ, Walter WK, Zicat BA. Squeaking in large diameter ceramic-on-ceramic bearings in total hip arthroplasty. J Arthroplast. 2015:30:282-5.

5. Langton DJ, Jameson SS, Joyce TJ, Webb J, Nargol AV. The effect of component size and orientation on the concentrations of metal ions after resurfacing arthroplasty of the hip. J Bone Joint Surg Br. 2008;90:1143-51.

6. Lewinnek GE, Lewis JL, Tarr R, Compere CL, Zimmerman JR. Dislocations after total hip-replacement arthroplasties. J Bone Joint Surg Am. 1978;60: 217-20

7. Elkins JM, Callaghan JJ, Brown TD. The 2014 frank Stinchfield award: the 'landing zone' for wear and stability in total hip arthroplasty is smaller than we thought: a computational analysis. Clin Orthop Relat Res. 2015;473:44152.

8. Danoff JR, Bobman JT, Cunn G, Murtaugh T, Gorroochurn P, Geller JA, Macaulay W. Redefining the Acetabular component safe zone for posterior approach Total hip Arthroplasty. J Arthroplast. 2016;31:506-11.

9. Murphy WS, Yun HH, Hayden B, Kowal JH, Murphy SB. The safe zone range for cup Anteversion is narrower than for inclination in THA. Clin Orthop Relat Res. 2018:476:325-35

10. Martin CT, Pugely AJ, Gao Y, Clark CR. A comparison of hospital length of stay and short-term morbidity between the anterior and the posterior approaches to total hip arthroplasty. J Arthroplast. 2013;28:849-54.

11. Higgins BT, Barlow DR, Heagerty NE, Lin TJ. Anterior vs. posterior approach for total hip arthroplasty, a systematic review and meta-analysis. J Arthroplast. 2015;30:419-34.

12. Kawasaki M, Hasegawa Y, Okura T, Ochiai S, Fujibayashi T. Muscle damage after Total hip Arthroplasty through the direct anterior approach for developmental dysplasia of the hip. J Arthroplast. 2017;32:2466-73.

13. Soderquist MC, Scully R, Unger AS. Acetabular placement accuracy with the direct anterior approach freehand technique. J Arthroplast. 2017;32:2748-54.

14. Kobayashi H, Homma Y, Baba T, Ochi H, Matsumoto M, Yuasa T, Kaneko K. Surgeons changing the approach for total hip arthroplasty from posterior to direct anterior with fluoroscopy should consider potential excessive cup anteversion and flexion implantation of the stem in their early experience. Int Orthop. 2016:40:1813-9.

15. Foissey C, Batailler C, Fary C, Luceri F, Servien E, Lustig S. Transitioning the total hip arthroplasty technique from posterior approach in lateral position to direct anterior approach in supine position-risk factors for acetabular malpositioning and the learning curve. Int Orthop. 2020. https://doi.org/10.1 007/s00264-020-04583-0.

16. Asayama I, Akiyoshi Y, Naito M, Ezoe M. Intraoperative pelvic motion in total hip arthroplasty. J Arthroplast. 2004;19:992-1007.

17. Grammatopoulos G, Pandit HG, da Assuncao R, Taylor A, McLardy-Smith P, De Smet KA, Murray DW, Gill HS. Pelvic position and movement during hip replacement. Bone Joint J. 2014;96:876-83.

18. Bohl DD, Nolte MT, Ong K, Lau E, Calkins TE, Della Valle CJ. ComputerAssisted Navigation Is Associated with Reductions in the Rates of Dislocation and Acetabular Component Revision Following Primary Tota Hip Arthroplasty. J Bone Joint Surg Am. 2019;101:250-6.
19. Brodt S, Nowack D, Jacob B, Krakow L, Windisch C, Matziolis G. Patient obesity influences pelvic lift during cup insertion in Total hip Arthroplasty through a lateral Transgluteal approach in supine position. J Arthroplast. 2017;32:2762-7

20. Kamenaga T, Hayashi S, Hashimoto S, Takayama K, Fujishiro T, Hiranaka T, Kuroda R, Matsumoto T. Intraoperative pelvic movement is associated with the body mass index in patients undergoing total hip arthroplasty in the supine position. J Orthop Sci. 2019;25:446-51.

21. Okamoto M, Kawasaki M, Okura T, Ochiai S, Yokoi H. Comparison of accuracy of cup position using portable navigation versus alignment guide in total hip arthroplasty in supine position. Hip Int. 2020. https://doi.org/1 $0.1177 / 1120700020908788$

22. Denninger M, Martel F, Rancourt D. A single step process to design a custom mattress that relieves trunk shear forces. Int J Mech Mater Des. 2011;7:1-16.

23. Martin HD, Savage A, Braly BA, Palmer IJ, Beall DP, Kelly B. The function of the hip capsular ligaments: a quantitative report. Arthroscopy. 2008;24:18895.

24. Shum GL, Crosbie J, Lee RY. Movement coordination of the lumbar spine and hip during a picking up activity in low back pain subjects. Eur Spine J. 2007;16:749-58.

\section{Publisher's Note}

Springer Nature remains neutral with regard to jurisdictional claims in published maps and institutional affiliations.

Ready to submit your research? Choose BMC and benefit from

- fast, convenient online submission

- thorough peer review by experienced researchers in your field

- rapid publication on acceptance

- support for research data, including large and complex data types

- gold Open Access which fosters wider collaboration and increased citations

- maximum visibility for your research: over $100 \mathrm{M}$ website views per year

At $\mathrm{BMC}$, research is always in progress.

Learn more biomedcentral.com/submission 